\title{
Cigarette smoke condensate inhibits ENaC $\alpha$-subunit expression in lung epithelial cells
}

\author{
H. Xu*, T.J. Ferro*,*,ף and S. Chu*,
}

ABSTRACT: Cigarette smoke has been associated with lung fluid accumulation and increased risk of acute respiratory distress syndrome. It was postulated that ENaC $\alpha$-subunit, which plays a critical role in lung fluid absorption, is affected by cigarette smoke.

Cigarette smoke condensate (CSC) was used to treat a human lung epithelial cell line. ENaC $\alpha$-subunit expression was measured using immunoblotting, quantitative PCR and promoterreporter assays.

The current authors found that CSC, without affecting cell survival, suppressed $\alpha$-subunit expression at the transcriptional level in a dose- and time-dependent fashion. This suppression is neither related to nicotine nor due to an increase of hydrogen peroxide levels in CSC-treated cells. CSC also suppressed $\alpha$-subunit core promoter activity. Dexamethasone, which activates the core promoter, was able to attenuate the inhibitory effect of CSC. However, in the presence of CSC, dexamethasone was unable to elicit a full-scale activation of $\alpha$-subunit expression. This inhibition of dexamethasone was partially reversed by withdrawal of CSC.

The present results demonstrate that cigarette smoke condensate inhibits ENaC $\alpha$-subunit expression at the transcriptional level through its promoter. This inhibition could be reversed by dexamethasone. The results also suggest that higher doses of dexamethasone may be needed to activate $\alpha$-subunit expression in smokers' lungs compared with nonsmokers' lungs, and that quitting smoking might improve the effectiveness of dexamethasone.

KEYWORDS: Ion channel, steroid, tobacco, transcription

A cute lung injury (ALI) and its more severe form, acute respiratory distress syndrome (ARDS), are syndromes associated with noncardiogenic pulmonary oedema and inflammation [1]. ALI/ARDS is a major cause of acute respiratory failure [2]. The high mortality of ALI is in part due to a lack of effective treatment, which reflects a paucity of knowledge of the disease mechanisms.

Pulmonary oedema is one of the important pathological components in ALI/ARDS. Many factors could cause aberrant lung fluid transport, which could affect both the formation and resolution of pulmonary oedema. Increasing evidence has shown that $\mathrm{ENaC}$, an amiloride-sensitive epithelial sodium channel, plays a critical role in lung fluid clearance [3]. The $\mathrm{ENaC}$ channel is composed of three subunits: $\alpha, \beta$ and $\gamma$ [4]. In the lung, the $\alpha$-subunit appears to be essential in fluid transport. Animals with inactivated $\alpha$-subunit, but active $\beta$ and $\gamma$ subunits, die shortly after birth with fluid-filled lungs [5]. Decreased expression of the $\alpha$-subunit predisposes animals to pulmonary oedema [6]. In humans, frequent lung infections and increased airway fluid accumulation occur in patients with pseudohypoaldosteronism, a genetic disease caused by mutations resulting in inactive $\mathrm{ENaC}[7,8]$.

Cigarette smoking affects general lung health, as it has been associated with inflammatory lung diseases and alveolar epithelial damage [9]. An association between cigarette smoking and a predisposition to ARDS has been established in a 15-yr cohort study [10]. Lung fluid accumulation induced by cigarette smoke could be an underlying mechanism for this association [11] However, the effect of cigarette smoke on ENaC expression in lung epithelia has not been studied.

The current authors chose to test the hypothesis that cigarette smoke condensate (CSC) decreases $\mathrm{ENaC} \alpha$-subunit expression in lung epithelial cells, because cigarette smoke causes lung epithelial damage and the $\alpha$-subunit is one of just a few key molecules involved in fluid transport across lung epithelia. Steroids have been used in treating some ALI patients and are known to activate $\mathrm{ENaC} \alpha$-subunit expression and to upregulate alveolar epithelial fluid clearance [12-14]. Therefore, possible interplay between
AFFILIATIONS

*McGuire VA Medical Center,

Depts of ${ }^{*}$ Medicine, and

•Physiology, Virginia Commonwealth University, Richmond, VA, USA

CORRESPONDENCE

S. Chu

McGuire VA Medical Center (151)

1201 Broad Rock Blv.

Richmond

VA 23249

USA

Fax: 18046755359

E-mail: schu@hsc.vcu.edu

Received:

February 052007

Accepted after revision:

May 092007

STATEMENT OF INTEREST

None declared. 
CSC and dexamethasone was examined. The results of the present study indicate that in human lung epithelial cells CSC inhibits $\alpha$-ENaC expression at the transcriptional level via the suppression of its core promoter. Whereas dexamethasone attenuates CSC-induced inhibition of $\alpha$-subunit expression, dexamethasone-induced $\alpha$-ENaC activation is markedly compromised in the presence of CSC. These results outline pathophysiological mechanisms explaining that: 1) smokers may be predisposed to pulmonary oedema; 2) smoker patients with pulmonary oedema and ALI may take longer to recover and have worse outcomes; and 3) current smokers may be less responsive to steroid therapy compared with previous smokers and nonsmokers.

\section{MATERIALS AND METHODS Cell culture and reagents}

HAE, a cell line derived from alveolar cell carcinoma of a 44yr-old female (American Type Culture Collection (ATCC) number: CRL-2170), was cultured in Leibovitz's L-15 medium supplemented with $10 \%$ foetal bovine serum. The BEAS-2B cell line was derived from normal human bronchial epithelium (ATCC number: CRL-9609). BEAS-2B cells were cultured in LHC-9 serum-free medium (Invitrogen, Carlsbad, CA, USA).

\section{Chemicals and antibodies}

CSC was supplied by Murty Pharmaceuticals (Lexington, KY, USA). It was prepared by smoking University of Kentucky's $1 \mathrm{R} 3 \mathrm{~F}$ standard research cigarettes on a smoke machine. Smoke particulates were collected on a filter and dissolved in dimethylsulphoxide (DMSO) at $40 \mathrm{mg} \cdot \mathrm{mL}^{-1}$. Dexamethasone, $2^{\prime}, 7^{\prime}$-dichlorofluorescin diacetate (DCFDA), Trolox, actinomycin D, propidium iodide (PI), acridine orange and Trypan Blue were purchased from Sigma (St Louis, MO, USA). $\alpha$-ENaC antibody was purchased from Santa Cruz Biotechnology (Santa Cruz, CA, USA).

\section{Treatment of human lung epithelial cells with CSC}

Cultures of HAE cells were grown to $70-80 \%$ confluence. Treatment with CSC, at a final concentration of $100 \mu \mathrm{g} \cdot \mathrm{mL}^{-1}$ in $0.25 \%$ DMSO, was carried out in Leibovitz's L-15 medium at $37^{\circ} \mathrm{C}$ for $6-24 \mathrm{~h}$ for time-course experiments in order to confirm the appropriate conditions with CSC. Control cells were treated with the same concentration of DMSO without CSC. For CSC dose-response experiments, cells were incubated for $24 \mathrm{~h}$ at $37^{\circ} \mathrm{C}$ with concentrations of CSC ranging 25$100 \mu \mathrm{g} \cdot \mathrm{mL}^{-1}$ in $0.25 \%$ DMSO.

\section{RNA and cDNA preparation}

Total RNA was prepared from cultured cell monolayers using the SV Total RNA Isolation System (Promega, Madison, WI, USA) following the manufacturer's protocol. The quality and quantity of the total RNA were examined by agarose gel electrophoresis and ultraviolet spectrophotometry. cDNA was prepared from total RNA using Moloney murine leukaemia virus reverse transcriptase (Invitrogen, San Diego, CA, USA). For subsequent PCR amplification, $40 \mathrm{ng}$ of the prepared cDNA was used as the template in each $20-\mu \mathrm{L}$ reaction.

\section{Conventional RT-PCR}

PCR experiments were performed on a Perkin Elmer DNA Thermal Cycler 480 (Perkin Elmer, Inc., Waltham, MA, USA) using the GoTaq Green Master Mix (Promega). Primers used in PCR are listed in table 1 . In each cycle, the reactions were denatured at $94^{\circ} \mathrm{C}$ for $1 \mathrm{~min}$, annealed at $62^{\circ} \mathrm{C}$ for $40 \mathrm{~s}$ and extended at $72^{\circ} \mathrm{C}$ for $40 \mathrm{~s}$. PCR products were analysed on $2 \%$ agarose gel. After electrophoresis, gel images were analysed by Aida Image Analyzer (Raytest Isotopenmeßgeräte $\mathrm{GmbH}$, Straubenhardt, Germany). The experiments were repeated three times.

\section{Quantitative RT-PCR}

Real-time PCR was performed using SYBR Green on the ABI 7500 Fast Real-Time PCR System (Applied Biosystems, Foster City, CA, USA). The final reaction mixture contained $40 \mathrm{ng}$ of cDNA, $200 \mathrm{nM}$ of each primer, $10 \mu \mathrm{L}$ of $2 \times$ SYBR Green PCR Master Mix (Applied Biosystems) and RNase-free water in a total volume of $20 \mu \mathrm{L}$ volume. All reactions were performed in triplicate. The PCR was performed with a hot-start denaturation step at $95^{\circ} \mathrm{C}$ for $10 \mathrm{~min}$, and was then carried out for 40 cycles at $95^{\circ} \mathrm{C}$ for $15 \mathrm{~s}$ and $60^{\circ} \mathrm{C}$ for $1 \mathrm{~min}$. The fluorescence was read during the reaction, allowing a continuous monitoring of the level of PCR product. The data was normalised to internal control glyceraldehyde-3-phosphate dehydrogenase mRNA. The sequences of primers used in real-time PCR are shown in table 1.

\section{Cell viability tests}

Cell viability after treatment with CSC was determined by Trypan Blue dye exclusion test and acridine orange/PI assay. In the latter assay, the staining solution was prepared by adding $100 \mu \mathrm{L}$ of $1 \mathrm{mg} \cdot \mathrm{mL}^{-1}$ PI (Sigma) and $100 \mu \mathrm{L}$ of $1 \mathrm{mg} \cdot \mathrm{mL}^{-1}$ acridine orange (Sigma) to $10 \mathrm{~mL}$ of PBS. Cell suspension was mixed 1:1 with the staining solution in a microcentrifuge tube. Stained cells were counted in a haemocytometer under an Olympus fluorescence microscope (Olympus America, Center Valley, PA, USA). PI-excluded cells were counted as viable and PI-stained cells were counted as dead cells. The experiments were repeated three to four times.

\section{Intracellular generation of hydrogen peroxide}

The fluorogenic substrate DCFDA is a cell-permeable dye that is oxidised to $2^{\prime}, 7^{\prime}$-dichlorofluorescein by hydrogen peroxide

\begin{tabular}{ll} 
TABLE 1 & $\begin{array}{c}\text { Oligonucleotides used in conventional and real- } \\
\text { time quantitative PCR }\end{array}$ \\
Name & \multicolumn{1}{c}{ Sequence } \\
\hline $\begin{array}{l}\text { Conventional PCR } \\
\alpha \text {-ENaC forward primer }\end{array}$ & GCCTGTCTGCGTCTAAAGC \\
$\alpha$-ENaC reverse primer & AGTGGACTGTGGAGGGTA \\
$\beta$-Actin forward primer & CATGAAGATCCTCACCGAGC \\
$\beta$-Actin reverse primer & GTGGACATCCGCAAAGACCT \\
Real-time quantitative PCR & GAGATTCCTGTCGCTTCC \\
$\alpha$-ENaC forward primer & CTGTGGAGGGCTAGAGTC \\
$\alpha$-ENaC reverse primer & TTGATTTGGAGGGATCTCG \\
GAPDH forward primer & CAATGACCCCTTCATTGACC \\
GAPDH reverse primer & \\
\hline &
\end{tabular}


and can therefore be used to monitor intracellular generation of hydrogen peroxide. In this assay, HAE culture medium was replaced by PBS solution containing $10 \mu \mathrm{M}$ DCFDA and incubated for $30 \mathrm{~min}$. Generation of hydrogen peroxide was measured using a fluorescence microscope $(485-530 \mathrm{~nm})$.

\section{mRNA stability assay}

HAE cells were treated with CSC at $100 \mu \mathrm{g} \cdot \mathrm{mL}^{-1}$ or vehicle for $24 \mathrm{~h}$. Actinomycin D was then added at $10 \mu \mathrm{g} \cdot \mathrm{mL}^{-1}$ for $0,6,12$, 18 and $24 \mathrm{~h}$. Total RNA was isolated at the end of the treatment using the SV Total RNA Isolation System (Promega). Real-time PCR was performed to quantify $\alpha$-ENaC transcript.

\section{Construction of $\alpha-E N a C$ promoter-reporter gene plasmids} The promoter-luciferase gene constructs were generated using PCR cloning and subsequent cloning into pGL3Basic (Promega). Inserts were confirmed by DNA sequencing. Four constructs of $\alpha$-ENaC, i.e. pGLa1931, pGLa791, pGLa332 and pGLa100 were used in the present study (fig. 1).

\section{Luciferase assay}

HAE cells at $\sim 80 \%$ confluence were transfected with $\alpha$-ENaC promoter-firefly luciferase gene constructs using FuGENE HD (Roche Applie Science, Indianapolis, IN, USA). Each promoter plasmid was cotransfected with the renilla luciferase expression vector pRL-TK (Promega) for calibration of transfection efficiency. According to the protocol of FuGENE HD, 4:2 ratio of FuGENE HD $(\mu \mathrm{L})$ to DNA $(\mu \mathrm{g})$ was selected. Following transfection, cells were incubated for 2 days. The Dual-Glo Luciferase Assay System (Promega) was used for measuring firefly and renilla luciferases according to the manufacturer's protocol. Readings were recorded on a Top-Count NXT Microplate Luminescence Counter (Packard, Meriden, CT, USA). The relative luciferase activity was calculated as firefly luciferase activity/renilla luciferase activity. The experiments were repeated three to five times.

\section{Western blotting}

Western blotting was performed as previously described [15]. Briefly, proteins were separated in 10\% SDS-PAGE gels

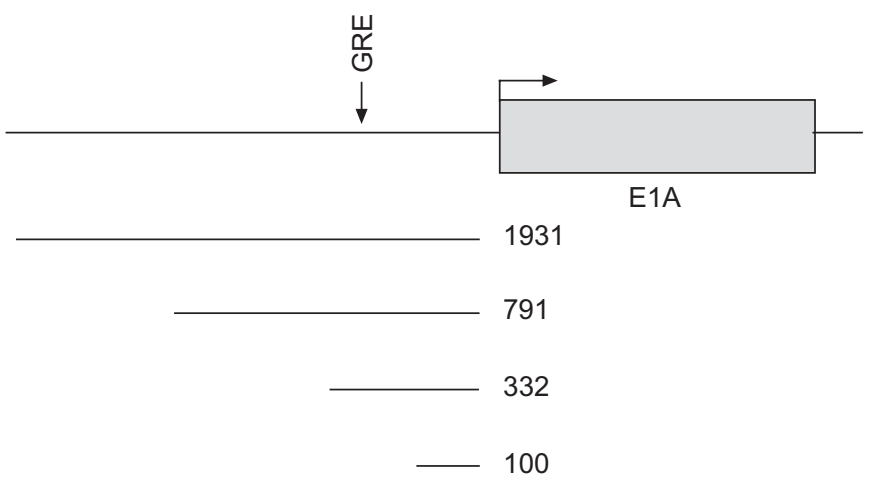

FIGURE 1. Construction of $\alpha$-ENaC promoter-reporter gene vectors. The top line depicts the genomic structure of the $5^{\prime}$ end of the $\alpha$-ENaC gene. The bent arrow marks the transcription initiation site. Lines below with numbers (base pairs in length) are promoter fragments inserted into the luciferase reporter gene vector pGL3Basic. The downward-pointing arrow shows the location of a conserved glucocorticoid-response element. E1A: exon $1 \mathrm{~A}$. and transblotted onto polyvinylidene difluoride membrane (Bio-Rad, Hercules, CA, USA). After a 1-h incubation in a blocking solution containing $20 \mathrm{mM}$ Tris-Cl, pH 7.5, $0.5 \mathrm{M}$ sodium chloride and 5\% nonfat dried milk, the membrane was incubated first with antibody at $4{ }^{\circ} \mathrm{C}$ overnight in an antibody buffer containing $20 \mathrm{mM}$ Tris- $\mathrm{Cl}, \mathrm{pH} 7.5,0.5 \mathrm{M}$ sodium chloride, $0.1 \%$ Tween 20 and $0.2 \%$ nonfat dried milk. The secondary antibody was incubated at room temperature for $1 \mathrm{~h}$. Three 10-min washes in a washing buffer $(20 \mathrm{mM}$ Tris-Cl, $\mathrm{pH} 7.5,0.5 \mathrm{M}$ sodium chloride and $0.1 \%$ Tween 20) were applied after each antibody reaction. Goat polyclonal anti- $\alpha-E N a C$ antibody was purchased from Santa Cruz Biotechnology. ECL kit (Amersham, Piscataway, NJ, USA) was used to develop the image.

\section{RESULTS \\ CSC inhibits expression of ENaC $\alpha$-subunit in HAE cells at the transcriptional level}

HAE cells were treated with increasing concentrations of CSC for $24 \mathrm{~h}$. The cells were then examined for $\alpha$-ENaC expression by conventional RT-PCR and real-time quantitative RT-PCR (fig. $2 a$ and b). It was found that CSC inhibits $\alpha-E N a C$ expression at a dose as low as $25 \mu \mathrm{g} \cdot \mathrm{mL}^{-1}$. At $100 \mu \mathrm{g} \cdot \mathrm{mL}^{-1}$ concentrations, the $\alpha$-ENaC mRNA level was only $\sim 23 \%$ of that of the control as determined by real-time RT-PCR. To further support this observation, the current authors treated HAE cells with $100 \mu \mathrm{g} \cdot \mathrm{mL}^{-1}$ of CSC for different time periods. As shown in figure $2 \mathrm{~d}, \mathrm{CSC}$ inhibited $\alpha$-ENaC expression with increasing time of treatment. By $24 \mathrm{~h}$, the $\alpha$-ENaC mRNA level fell to $\sim 19 \%$ of that of the control cells. These data confirm that CSC inhibits $\alpha$-ENaC expression in HAE cells in a dose- and time-dependent manner. At the protein level, the same trend was seen in immunoblots using various doses of CSC (fig. 2c). Compared with the regulation at the mRNA level, the $\alpha$-ENaC protein level appears to be more constant. This could be due to a time delay from the regulation at the mRNA level to the changes shown at the protein level. Furthermore, the half-life of the $\alpha$-subunit protein might be longer than its mRNA. To confirm that the inhibitory effect of CSC on $\alpha-\mathrm{ENaC}$ is present not only in HAE cells but also in other human lung epithelial cells, the quantitative RT-PCR experiments were repeated in BEAS-2B cells. BEAS-2B cells are derived from noncancerous normal human bronchial epithelium. Compared with HAE cells, it was found that $\alpha$-ENaC mRNA levels in BEAS-2B cells were similarly inhibited by CSC in a dose-dependent fashion (fig. 2e), suggesting that the inhibitory effect of CSC on $\alpha$-ENaC expression is not cell-line specific.

Nicotine is a known cytotoxic component in cigarette smoke. Whether nicotine is an effective $\alpha$-ENaC inhibitor in CSC was unknown. Therefore, the current authors tested possible roles of nicotine in $\alpha$-ENaC expression. Using real-time quantitative PCR, it was found that nicotine, in up to $1 \mu \mathrm{M}$ concentrations, did not have any effect on $\alpha$-ENaC expression over a $24-\mathrm{h}$ period (data not shown), suggesting that the inhibitory effect of CSC on $\alpha$-ENaC expression derives from non-nicotine components in CSC.

\section{Changes in $\alpha-E N a C$ expression is not associated with cell death}

It was investigated whether the inhibition of $\alpha-\mathrm{ENaC}$ occurs only in dying cells. To answer this question, the present 
a)
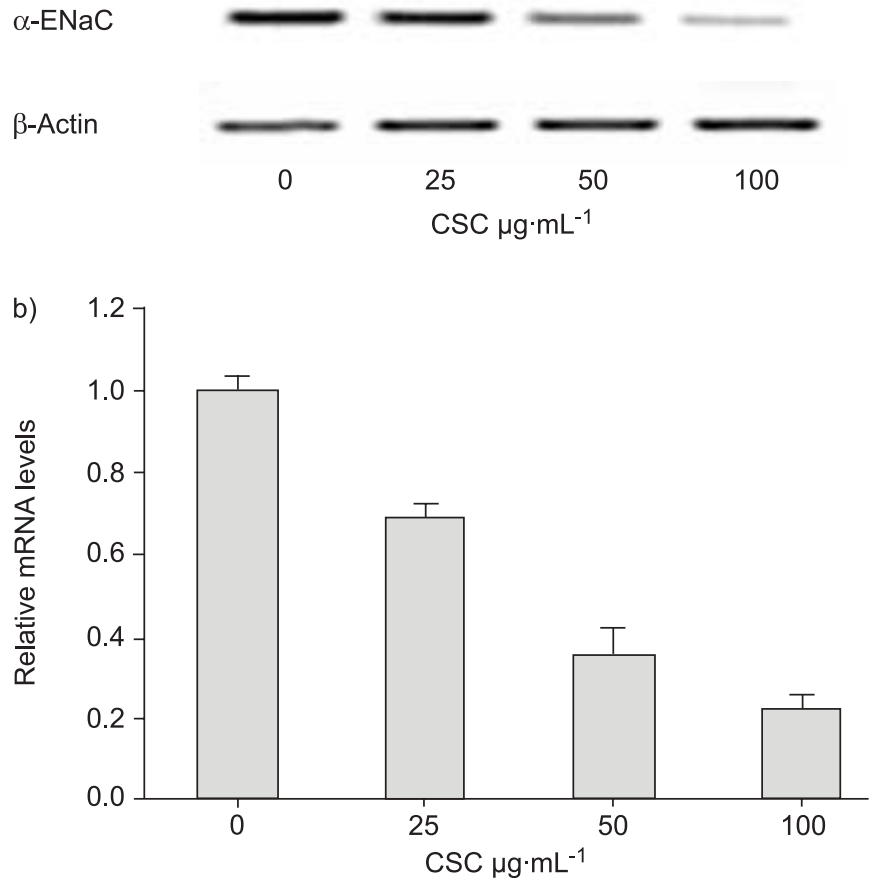

c) $\alpha-\mathrm{ENaC}$

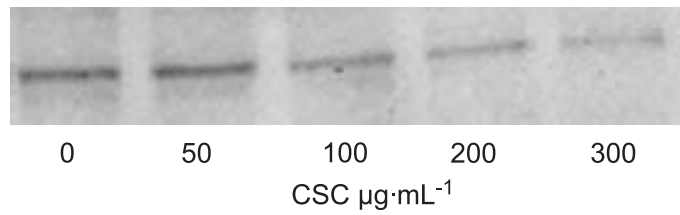

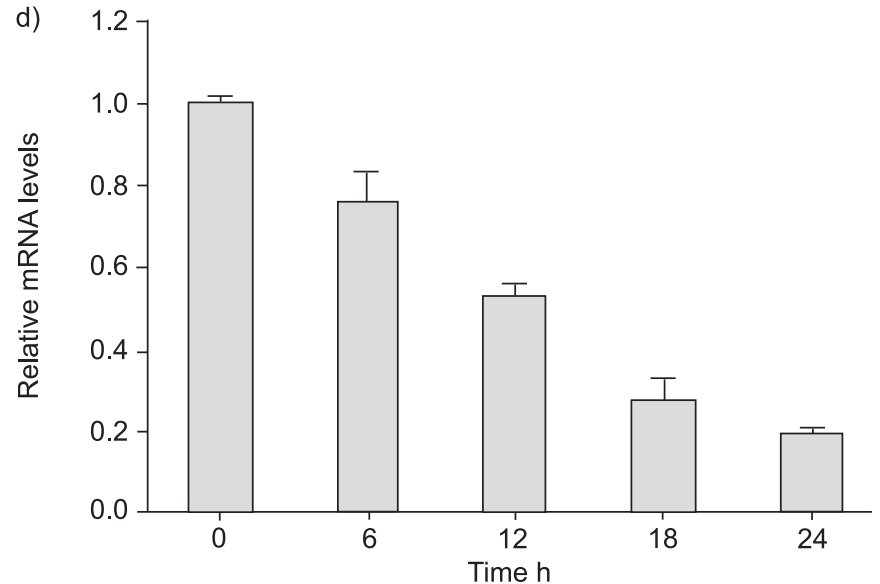

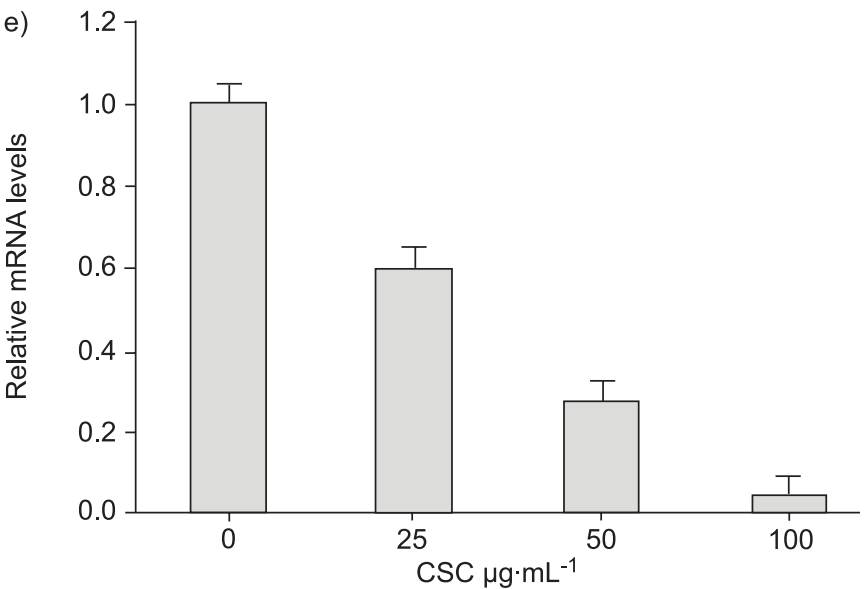

FIGURE 2. Cigarette smoke condensate (CSC) inhibits $\alpha$-ENaC expression in HAE cells. a) RT-PCR amplification of $\alpha$-ENaC and $\beta$-actin in HAE cells treated with CSC at the concentrations indicated. To avoid the plateaux at the end of amplification, 29 cycles were used for $\alpha$-ENaC amplification and 24 cycles were used for $\beta$-actin amplification. b) Real-time quantitative RT-PCR amplification of $\alpha$-ENaC cDNA. mRNA samples were isolated from HAE cells treated with CSC for $24 \mathrm{~h}$ at the concentrations indicated. Glyceraldehyde-3-phosphate dehydrogenase (GAPDH) was amplified as internal calibration. Relative levels of mRNA were calculated as $\alpha$-ENaC/GAPDH ratio. c) Immunoblot showing intensity changes of $\alpha$-ENaC protein in HAE cells. Whole-cell lysates were prepared from cells treated with CSC for $24 \mathrm{~h}$ at various concentrations. An equal amount of proteins was loaded in each lane $\left(30 \mu \mathrm{g} \cdot\left(\mathrm{ane} \mathrm{e}^{-1}\right)\right.$. The experiment was repeated three times, with similar results. d) Real-time quantitative RT-PCR amplification of $\alpha$-ENaC cDNA in HAE cells treated with $100 \mu \mathrm{g} \cdot \mathrm{mL}^{-1} \mathrm{CSC}$ for different time periods as indicated. e) Real-time quantitative RT-PCR amplification of $\alpha$-ENaC cDNA in BEAS$2 \mathrm{~B}$ cells. The cells were treated with $\mathrm{CSC}$ for $24 \mathrm{~h}$ at the concentrations indicated. GAPDH was amplified as internal calibration. Relative levels of mRNA were calculated as $\alpha-\mathrm{ENaC} / \mathrm{GAPDH}$.

authors examined whether CSC induces cell death in the concentration range used. HAE cells were exposed to increasing concentrations of CSC for $24 \mathrm{~h}$. Both Trypan Blue and acridine orange/PI were used to test cell viability. In the acridine orange/PI assay, cell numbers remained nearly constant up to $200 \mu \mathrm{g} \cdot \mathrm{mL}^{-1}$ of CSC. A similar stable trend was seen in cell viability, which was not affected by CSC concentrations up to $200 \mu \mathrm{g} \cdot \mathrm{mL}^{-1}$ and decreased slightly at $300 \mu \mathrm{g} \cdot \mathrm{mL}^{-1}$ (fig. 3a). The decline of cell numbers at $300 \mu \mathrm{g} \cdot \mathrm{mL}^{-1}$ of CSC could be a result of either increased cell death or delayed cell proliferation. Both conditions may exist in CSC-treated cells. However, delayed cell growth is more likely, because of the more stable trend in cell viability. Prolonged treatment with $100 \mu \mathrm{g} \cdot \mathrm{mL}^{-1}$ of CSC up to $72 \mathrm{~h}$ did not result in any notable changes in either cell number or viability (fig. 3b). Trypan Blue exclusion assay showed similar results (data not shown). These results demonstrate that the majority of HAE cells remain viable for $24 \mathrm{~h}$ in the presence of $200 \mu \mathrm{g} \cdot \mathrm{mL}^{-1} \mathrm{CSC}$ and for $72 \mathrm{~h}$ in the presence of $100 \mu \mathrm{g} \cdot \mathrm{mL}^{-1}$ CSC, and suggest that a CSC-induced decrease in $\alpha$-ENaC expression is not related to cell death.

\section{Block of CSC-induced oxidative stress does not change its inhibitory effect on $\alpha$-ENaC}

It is known that cigarette smoke induces oxidative stress in the lung [16]. When HAE cells were treated with $100 \mu \mathrm{g} \cdot \mathrm{mL}^{-1} \mathrm{CSC}$ for $24 \mathrm{~h}$, hydrogen peroxide production increased, as detected by DCFDA (fig. 4). Therefore, the current authors suspected that oxidative stress is a downstream signal that mediates CSCinduced inhibition of $\alpha$-ENaC expression. However, when HAE cells were treated with CSC in the presence of the antioxidant Trolox $\left(100 \mu \mathrm{M} \cdot \mathrm{mL}^{-1}\right)$, the inhibitory effect of CSC on $\alpha$-ENaC expression was not changed. Furthermore, treating HAE cells directly with hydrogen peroxide in concentrations 

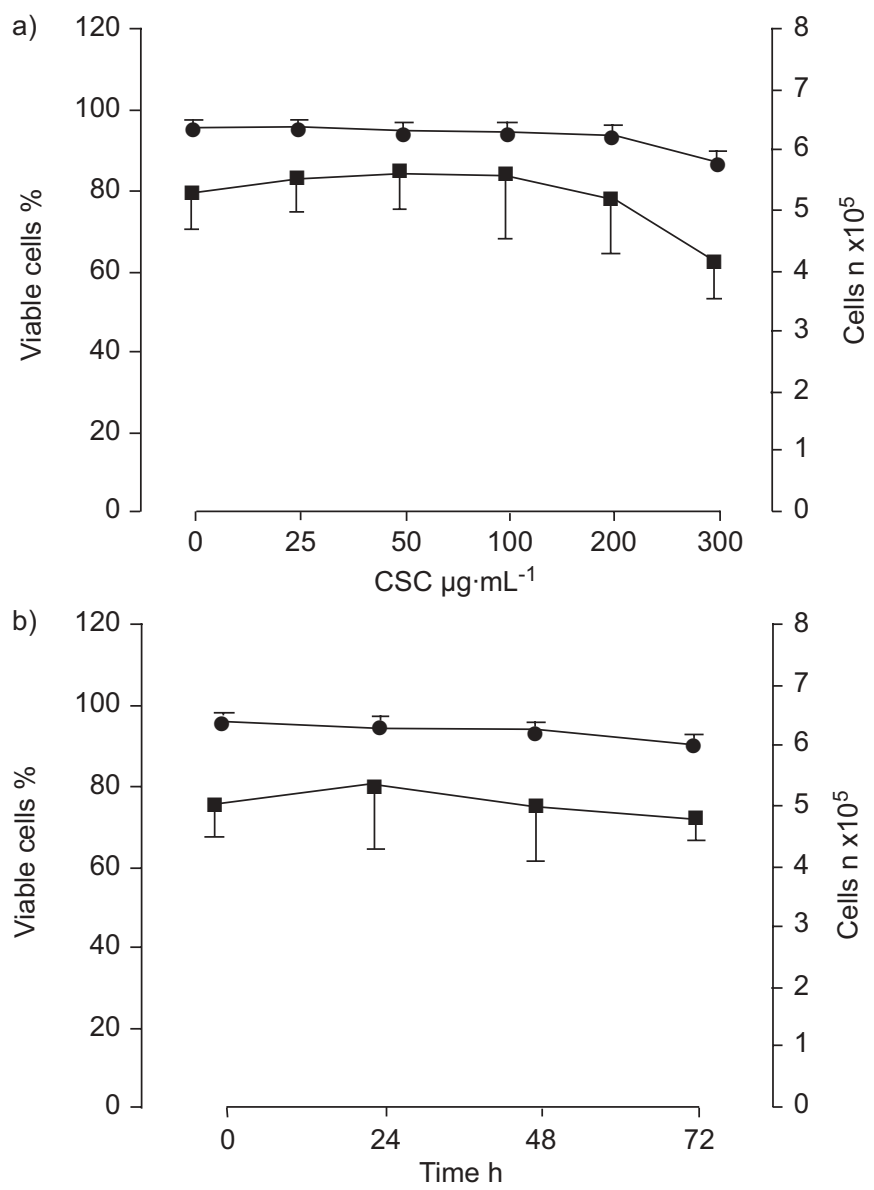

FIGURE 3. Effect of cigarette smoke condensate (CSC) on cell survival. a) HAE cells were treated with CSC for $24 \mathrm{~h}$ at the concentrations indicated. At the end of the treatment, the cells were stained with acridine orange/propidium iodide. Total number of cells on $8 \mathrm{~cm}^{2}$ culture surface and the number of viable cells were counted and averages were plotted $(n=3)$. b) Similar plots as in a) but the cells were treated with $100 \mu \mathrm{g} \cdot \mathrm{mL}^{-1} \mathrm{CSC}$ for different time periods $(\mathrm{n}=3)$. $\mathbf{\square}$ : total cell numbers; $\bullet$ : percentages of viable cells.

up to $1.0 \mathrm{mM}$ for $24 \mathrm{~h}$ did not result in changes in $\alpha$-ENaC mRNA (data not shown). These results imply that oxidative stress is not involved in CSC-induced inhibition of $\alpha$-ENaC expression.

\section{CSC inhibits $\alpha$-ENaC expression, via a 232-bp sequence in the promoter, but not mRNA stability}

The changes in $\alpha$-ENaC expression at the transcriptional level could be the result of regulation of transcription initiation, transcript stability, or both. The turnover rate of $\alpha$-ENaC transcript in HAE cells was examined using transcription inhibitor actinomycin D, in the presence of CSC or vehicle. Cells were collected at various time-points after incubation with actinomycin $\mathrm{D}$, and $\alpha$-ENaC mRNA was quantified using real-time RT-PCR. The results show that the rates of transcript degradation are very similar between CSC- and vehicle-treated cells, with $\sim 40 \%$ of $\alpha$-ENaC transcripts remaining at the end of a 24-h incubation (fig. 5). This finding supports the possibility that CSC inhibits $\alpha$-ENaC transcription initiation.
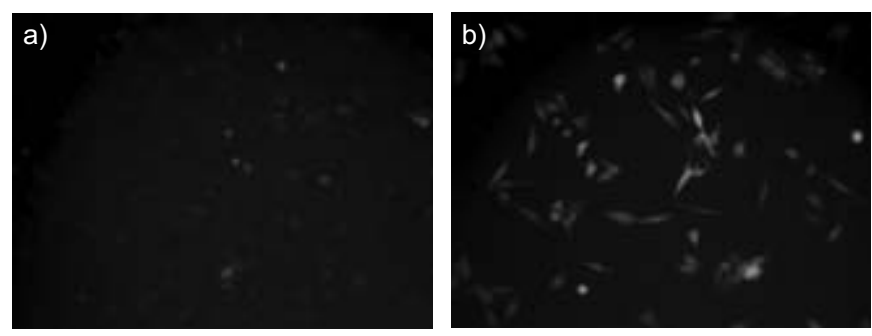

FIGURE 4. Cigarette smoke condensate (CSC) activates hydrogen peroxide production in a) control and b) CSC-treated HAE cells. Production of hydrogen peroxide in HAE cells was measured with $2^{\prime}, 7^{\prime}$-dichlorofluorescin diacetate, a cellpermeable fluorogenic dye that is oxidised by hydrogen peroxide. Fluorescence microscopic images show cells containing fluorescent oxidised product $2^{\prime}, 7^{\prime}$ dichlorofluorescein.

The current authors subsequently examined the possible effect of CSC on $\alpha-\mathrm{ENaC}$ promoter activity. A set of $\alpha-\mathrm{ENaC}$ promoter-luciferase vectors was constructed (fig. 1). HAE cells were transfected with the promoter-luciferase vectors and treated with CSC. The results show that luciferase activities of several promoter constructs were decreased in the cells treated with CSC (fig. 6a). The most significant decline in promoter activity was seen in the 332-base pair (bp) construct, whereas no changes were present in the 100-bp construct. This difference indicates that a 232-bp sequence, which is absent in the 100-bp construct, is most responsive to CSC treatment. All other promoter fragments containing this 232-bp sequence showed a CSC-induced inhibitory effect. The 232-bp sequence appears to include the core promoter, as it displays the highest baseline activity. This sequence also contains a glucocorticoid-responsive element (GRE). Therefore, the effect of glucocorticoid was tested on the same set of $\alpha-\mathrm{ENaC}$ promoter vectors using dexamethasone. Compared with the CSC treatment, and regardless of the directions of regulation, the relative scale of regulation closely matched that

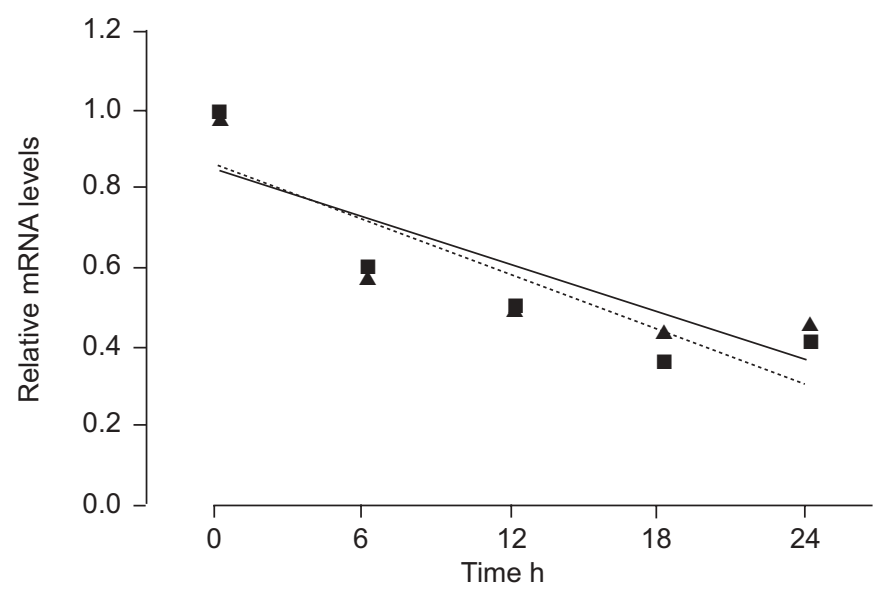

FIGURE 5. $\alpha$-ENaC transcript stability. HAE cells were treated with $100 \mu \mathrm{g} \cdot \mathrm{mL}^{-1}$ cigarette smoke condensate ( $\boldsymbol{\square}$ and $\longrightarrow$ ) or dimethylsulphoxide ( $\boldsymbol{\Lambda}$ and …......) for $24 \mathrm{~h}$. Actinomycin $\mathrm{D}$ was added to a final concentration of $10 \mu \mathrm{g} \cdot \mathrm{mL}^{-1}$ and the cells were incubated for the time period indicated. The cells were then harvested and the levels of $\alpha$-ENaC mRNA were determined by real-time quantitative RT-PCR. 

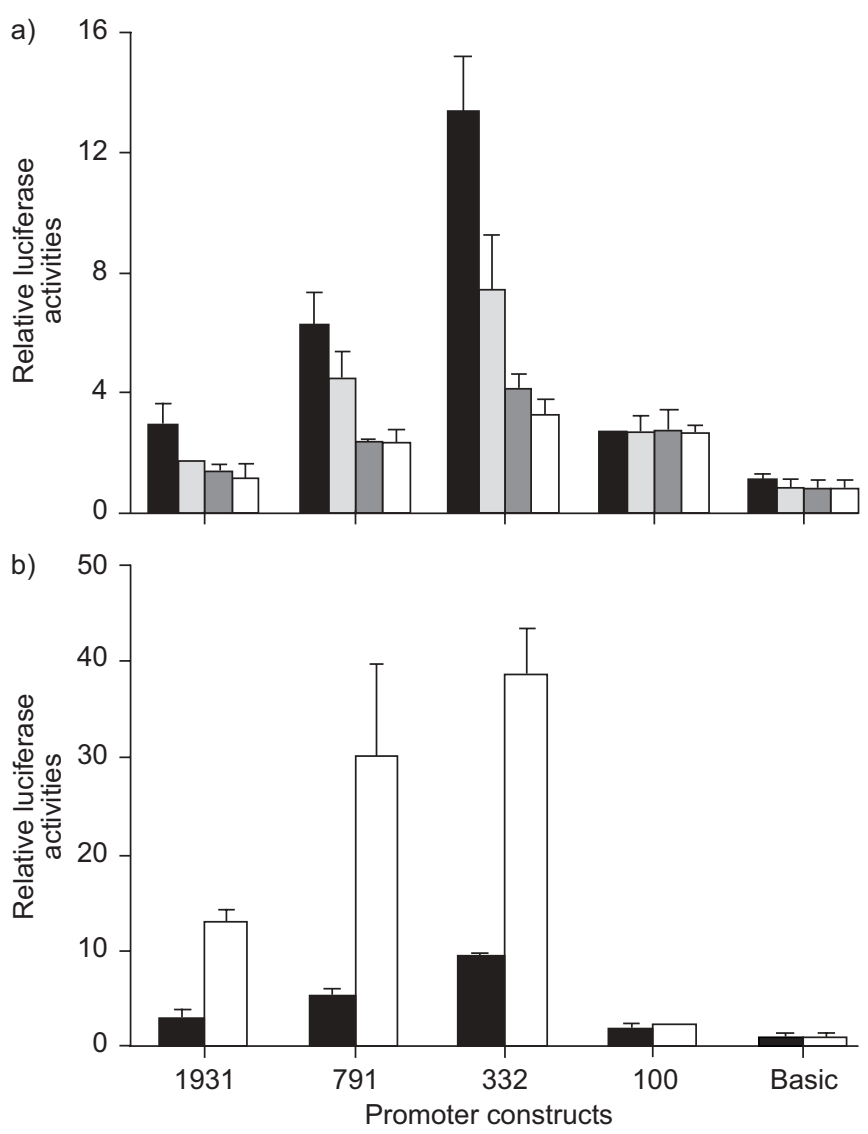

FIGURE 6. Cigarette smoke condensate (CSC) inhibits $\alpha$-ENaC promoter activity in HAE cells. a) HAE cells were transfected with $\alpha$-ENaC promoter-luciferase vectors and treated with various amounts of CSC for $24 \mathrm{~h}\left(\mathbf{\square}: 0 \mu \mathrm{g} \cdot \mathrm{mL}^{-1}\right.$; $\left.25 \mu \mathrm{g} \cdot \mathrm{mL}^{-1} ; \square: 50 \mu \mathrm{g} \cdot \mathrm{mL}^{-1} ; \square 100 \mu \mathrm{g} \cdot \mathrm{mL}^{-1}\right)$. Average relative luciferase activities are shown for each promoter fragment and each dose of CSC $(n=3)$. b) HAE cells were transfected with the same set of $\alpha$-ENaC promoter-luciferase vectors. The cells were treated with either vehicle $(\mathbf{\square})$ or $100 \mathrm{nM}$ dexamethasone $(\square)$ for $24 \mathrm{~h}$ before measuring luciferase activity. Average relative luciferase activities are shown $(n=3)$.

of CSC on the entire set of promoter vectors (fig. 6b), suggesting the importance of the 232-bp sequence for both CSC and dexamethasone.

\section{Dexamethasone attenuates the inhibitory effect of CSC on $\alpha$-ENaC expression}

As both CSC and dexamethasone regulate $\alpha$-ENaC expression via the 232-bp core promoter, the current authors tested whether dexamethasone would attenuate the inhibitory effect of CSC. In the present study, HAE cells were treated for $24 \mathrm{~h}$ with $100 \mu \mathrm{g} \cdot \mathrm{mL}^{-1}$ CSC in the presence and absence of dexamethasone. $\alpha$-ENaC mRNA expression was quantified using real-time quantitative RT-PCR. As was expected, at $1 \mathrm{nM}$ concentration, dexamethasone reversed the CSC-induced inhibition nearly completely. Cotreatment with $100 \mathrm{nM}$ dexamethasone resulted in a net increase of $\alpha$-ENaC mRNA (fig. 7a), suggesting that dexamethasone is able to reverse CSCinduced inhibition of $\alpha$-ENaC expression. Promoter-reporter assays to test the effect of dexamethasone were also performed. Consistent with the quantitative PCR results, dexamethasone was able to attenuate the inhibitory effect of CSC on the
$\alpha-\mathrm{ENaC}$ promoter (fig. 7b). However, compared with the realtime quantitative RT-PCR results, a higher concentration of dexamethasone was required to completely reverse the CSC inhibitory effect. This may suggest that dexamethasone increases $\alpha-\mathrm{ENaC}$ mRNA levels, not only through the regulation of its promoter but also other nonpromoter mechanisms. This may also be due to differences in the production or stability between $\alpha$-ENaC mRNA and firefly luciferase protein. At the protein level, immunoblotting shows a similar trend as that at the mRNA level (fig. 7c).

\section{CSC suppresses dexamethasone-induced $\alpha$-ENaC expression}

As many other studies have shown that smokers are less responsive to steroid treatment compared with nonsmokers [17-19], the current authors suspected that CSC might have a negative effect on dexamethasone-induced activation. In a similar real-time quantitative RT-PCR experiment, $100 \mathrm{nM}$ dexamethasone increased $\alpha$-ENaC mRNA level 40-fold. However, in the presence of $100 \mu \mathrm{g} \cdot \mathrm{mL}^{-1}$ of CSC, dexamethasone induced only a four-fold increase of $\alpha$-ENaC mRNA (fig. 8a). The same trend was seen in reporter gene assays using the most active 332-bp $\alpha-\mathrm{ENaC}$ promoter fragment. Dexamethasone alone increased the promoter activity fourfold, whereas in the presence of $100 \mu \mathrm{g} \cdot \mathrm{mL}^{-1}$ CSC, dexamethasone-induced activation was nearly completely abolished (fig. 8b). To model smokers' lungs, CSC was added to HAE cells $24 \mathrm{~h}$ prior to the treatment with dexamethasone. In the cells pre-treated with CSC, dexamethasone increased $\alpha$-ENaC mRNA five-fold. Interestingly, when CSC was withdrawn, dexamethasone was able to increase $\alpha-\mathrm{ENaC}$ mRNA 15 -fold (fig. 8c). These results suggest a negative role of CSC in dexamethasone-related activation of $\alpha$-ENaC expression. In addition, the results show that CSC-induced inhibition of $\alpha$-ENaC is, to a certain extent, reversible. Since CSC at this concentration does not cause cell death (fig. 3b), complete recovery of $\alpha-\mathrm{ENaC}$ expression after CSC withdrawal may be possible.

\section{DISCUSSION}

Noncardiogenic pulmonary oedema may result from a wide range of pathological stimuli, such as inflammation, gas inhalation, drug reaction and high-altitude hypoxia. Due to the diverse nature of aetiology, it has been difficult to determine the exact mechanisms involved in the formation of pulmonary oedema. However, it is recognised that injury to the lung microvascular circulation results in increased permeability of capillary endothelium, leading to increased transvascular fluid filtration into the perimicrovascular interstitium. If the epithelial layer is also damaged, the fluid will move further across the epithelial layer into the airspace [12]. Absorption of the fluid in the airspace is dependent on $\mathrm{Na}^{+}$absorption, which is mediated by apical $\mathrm{Na}^{+}$channels and basal lateral ion pumps in the lining epithelial cells. The function of these transport molecules is therefore important during the recovery of pulmonary oedema. The $\mathrm{ENaC} \mathrm{Na}{ }^{+}$channel is one of the transport molecules whose role in lung fluid clearance has been recognised in recent years [20].

In the absence of other factors, defective $\mathrm{ENaC}$ or deficient $\mathrm{ENaC}$ function per se may lead to accumulation of lung fluid in 

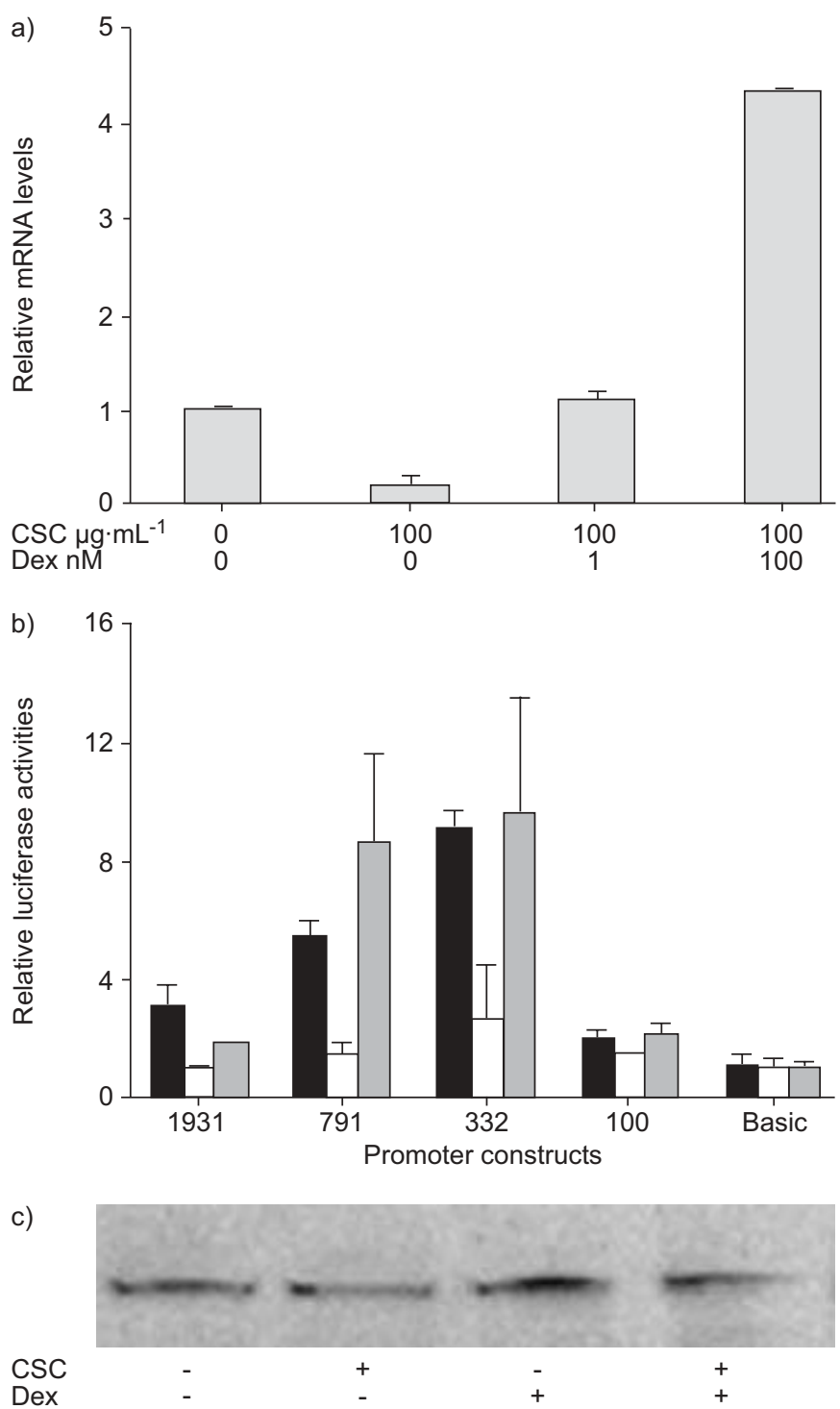

FIGURE 7. Dexamethasone attenuates cigarette smoke condensate (CSC)induced inhibition of $\alpha$-ENaC expression. a) HAE cells were treated with either CSC or both CSC and dexamethasone (Dex) for $24 \mathrm{~h}$ at the doses indicated. Total mRNA was then isolated and used in real-time quantitative RT-PCR to amplify a fragment in $\alpha$-ENaC. Average relative $\alpha$-ENaC mRNA levels were calculated with the control cells set at $1(n=3)$. b) HAE cells were transfected with the same set of $\alpha$-ENaC promoter-luciferase vectors. The cells were then treated for $24 \mathrm{~h}$ with either

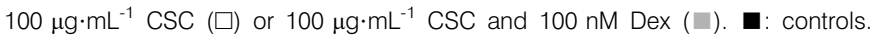
Average relative luciferase activities are shown $(n=3)$. c) HAE cells were treated with $100 \mu \mathrm{g} \cdot \mathrm{mL}^{-1} \mathrm{CSC}, 100 \mathrm{nM}$ Dex, or both, for $24 \mathrm{~h}$. Whole-cell lysates were prepared for immunoblotting analysis for $\alpha$-ENaC protein. The experiment was performed twice. A representative immunoblot is shown, with treatments indicated.

the airspace. This finding has been reported in animals as well as in patients with systemic pseudohypoaldosteronism [6, 7]. Furthermore, deficient $\mathrm{ENaC}$ has been reported as a cofactor in the formation of hypoxia-related pulmonary oedema [21, 22]. In a different manner to most cases of pulmonary oedema, which is due to increased fluid exodus from microcirculation, the blockage of the entry pathway of lung fluid at lung epithelia might result in lung fluid accumulation with no or mild symptoms. Therefore, compromised lung fluid absorption may predispose patients to ALI when other insults are present.

Cigarette smoke results in damage to lung epithelia. Its ability to induce pulmonary oedema has been supported by animal studies [11]. Compared with smoke inhalation injuries in burn patients, clinical presentations of cigarette smoke-induced lung injury are not as acute and profound, due to a lack of complications, such as carbon monoxide poisoning, and hypoxia and thermal wounds in the upper airway. However, cigarette smoke-induced lung injury may form a histological or biochemical base upon which additional insults could bring out clinical manifestations more quickly. Consistent with the theory that smokers are predisposed to lung injury and pulmonary oedema, a 15-yr cohort study found an association between cigarette smoking and risk of ALI/ARDS [10]. Due to the important role of $\mathrm{ENaC}$ in lung fluid clearance and the prominent function of its $\alpha$-subunit [5, 23], the present results, which indicate that CSC inhibits $\alpha$-ENaC expression in lung epithelial cells, provide a possible explanation at the molecular level for the association between cigarette smoking and ALI. The results suggest a mechanism by which smokers are more prone to pulmonary oedema and ALI than nonsmokers, and explain why outcome in smokers with pulmonary oedema is worse than in nonsmokers.

In the present study, human lung epithelial cell lines were used, and were treated with cigarette smoke condensate produced from research cigarettes in DMSO. Results from cell lines do not always demonstrate in vivo events, and treatment with CSC does not exactly replicate in vivo responses to smoke exposure. However, when carefully designed, these settings allow us to predict mechanisms that might be relevant to in vivo situations. To increase this chance, the current authors tested surfactant protein $\mathrm{A}$ and $\mathrm{ClC}-2$ chloride channel protein expression in HAE cells and found that both are expressed (data not shown). The BEAS-2B lung epithelial cell line derived from a normal individual was also used. The CSC dose range used, although difficult to compare with that in human airways in smokers, is similar to those previously reported $\left(0-500 \mu \mathrm{g} \cdot \mathrm{mL}^{-1}\right)[24,25]$. To demonstrate specificity, dosedependence and time-dependence were examined. The current authors therefore believe that the observations made in the present study suggest a trend in the lungs of smokers.

Cigarette smoke regulates gene expression at the transcriptional level. The pool of steady state mRNA is dependent on the production and degradation of mRNA. Cigarette smoke may regulate both production and degradation of mRNA by changing promoter activity and transcript stability, respectively [26]. The present results show, however, that $\alpha$-ENaC transcript stability in CSC-treated cells is very similar to that in control cells, supporting a role of the altered promoter activity. The latter was confirmed in promoter studies in which the activity of a 232-bp core promoter sequence appears to be most significantly inhibited. The 232-bp core promoter contains the GRE domain, which mediates glucocorticoid-induced activation. The current authors believe that the GRE domain in this promoter also supports promoter activity through other nonglucocorticoid mechanisms. This is because, even in the absence of glucocorticoids and serum, mutation of the GRE 

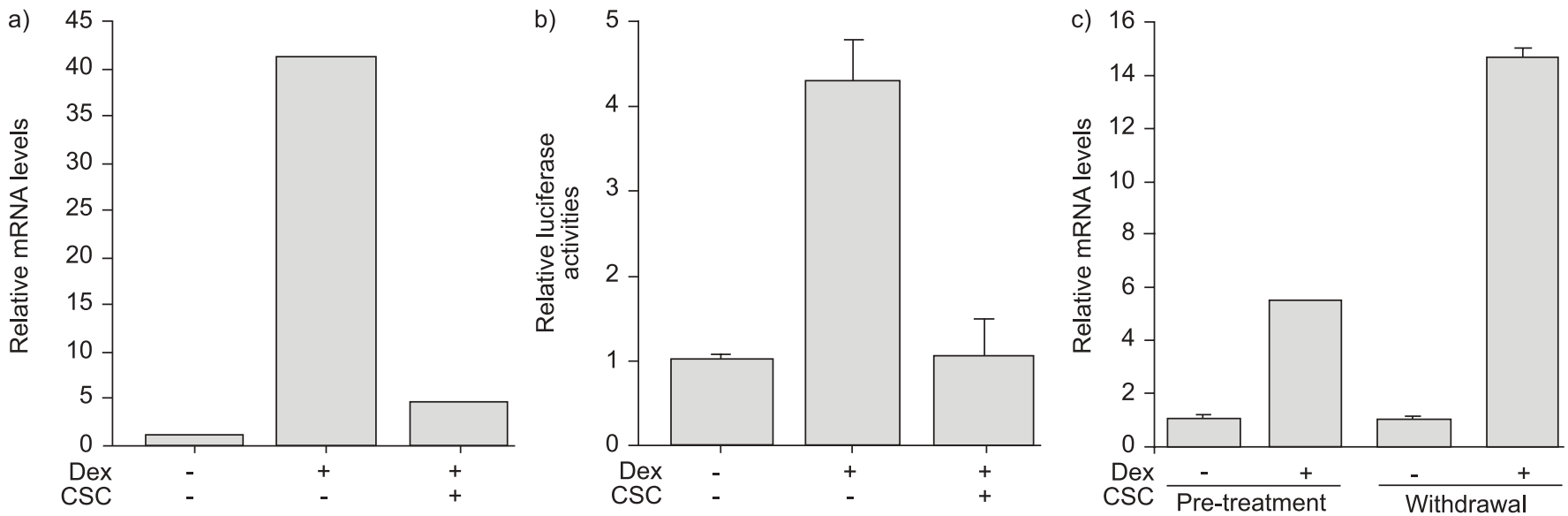

FIGURE 8. Cigarette smoke condensate (CSC) suppresses dexamethasone (Dex)-induced activation of $\alpha$-ENaC expression. a) HAE cells were treated with either $100 \mathrm{nM}$ Dex or both $100 \mathrm{nM}$ Dex and $100 \mu \mathrm{g} \cdot \mathrm{mL}^{-1} \mathrm{CSC}$ for $24 \mathrm{~h}$. Total mRNA was then isolated and real-time quantitative RT-PCR was used to quantify the levels of $\alpha$-ENaC $\mathrm{mRNA}$ ( $\mathrm{n}=3$ ). The level of $\alpha$-ENaC mRNA in the control cells was set at 1. b) HAE cells were transfected with the $\alpha$-ENaC promoter-luciferase vector 332 . The cells were then treated for $24 \mathrm{~h}$ with either $100 \mathrm{nM}$ Dex or $100 \mathrm{nM}$ Dex and $100 \mu \mathrm{g} \cdot \mathrm{mL}^{-1} \mathrm{CSC}$. Average relative luciferase activities are shown with the control cells set at 1 ( $\mathrm{n}=3$ ). c) Quantification of $\alpha$-ENaC mRNA by real-time quantitative RT-PCR. In the CSC pre-treatment group, HAE cells were treated for $48 \mathrm{~h}$. For the first 24 -h period, only $100 \mu \mathrm{g} \cdot \mathrm{mL}^{-1} \mathrm{CSC}$ was added. For the next $24 \mathrm{~h}$, the cells were treated with $100 \mu \mathrm{g} \cdot \mathrm{mL}^{-1} \mathrm{CSC}$ in the presence and absence of $100 \mathrm{nM}$ Dex. The relative $\alpha$-ENaC mRNA level in the cells without Dex was set at 1 . In the CSC withdrawal group, the cells were also treated for $48 \mathrm{~h}$. For the first $24 \mathrm{~h}$, only $100 \mu \mathrm{g} \cdot \mathrm{mL}^{-1} \mathrm{CSC}$ was used. However, for the next $24 \mathrm{~h}$, CSC was withdrawn and the cells were treated with either vehicle or $100 \mathrm{nM}$ Dex. The relative $\alpha$-ENaC mRNA level in the cells treated with vehicle for the second $24 \mathrm{~h}$ was set at 1 ( $\mathrm{n}=3$ ).

sequence remarkably reduces the baseline promoter activity (data not shown).

In contrast to dexamethasone, which acts on the GRE domain through glucocorticoid receptor (GR) binding, exact interactions between CSC and the core promoter are unknown and could be complex. Some CSC components might interact with dexamethasone, GR or their complex, through which they may regulate the $\alpha$-ENaC promoter. Although the role of the glucocorticoid/GR/GRE pathway in this regulation cannot be excluded, especially when dexamethasone is present, it can be concluded that other nonglucocorticoid pathways are involved. This is because CSC markedly inhibits $\alpha$-ENaC promoter activity in cells cultured in serum-free medium where glucocorticoids are not present and GR is not activated.

Different compounds in CSC may regulate gene expression through various pathways. Oxidative stress is increased in smokers' lungs and can regulate gene expression. Although CSC treatment increases hydrogen peroxide production in HAE cells, the other results of the present study do not support a role of hydrogen peroxide in CSC-induced inhibition of $\alpha$ $\mathrm{ENaC}$. Nicotine is a well-known toxic component in cigarette smoke and is capable of gene regulation at the transcriptional level [27]. However, treatment of HAE cells with nicotine at $1 \mu \mathrm{m}$ did not result in a similar inhibition of $\alpha$-ENaC to that caused by CSC. In addition to nicotine, many other compounds in cigarette smoke may possess regulatory functions in cells. One of the examples is dioxin, along with other agonists of the aryl hydrocarbon receptor (AhR). AhR is a transcription factor that, upon activation by ligands, binds to the xenobioticresponsive element in promoters and activates gene expression [28]. Cigarette smoke may also evoke methylation of $\mathrm{CpG}$ islands in promoters, leading to the inhibition of gene expression [29, 30]. These reported mechanisms suggest that regulation of $\alpha-\mathrm{ENaC}$ expression by CSC could be very complex and could involve multiple regulatory pathways.

Steroids are used in some pulmonary oedema patients and they significantly upregulate alveolar fluid clearance in animals $[12,14]$. Although the exact therapeutic role of steroids in pulmonary oedema is not yet clear, it is well documented that steroids significantly activate expression of $\alpha$-ENaC $[13$, 31,32 ]. $\alpha$-ENaC, in addition to other therapeutic benefits that steroids may have, might promote clearance of lung oedema fluid, and its benefit in ALI has been shown in animal studies $[33,34]$. Compared with nonsmokers, smokers are generally less responsive to steroid treatment [18]. While the reason for this difference could be complex, the present results indicate that cigarette smoke may, to a considerable extent, prevent steroids from activating $\mathrm{ENaC}$ expression and thus limit its ability to promote lung oedema fluid absorption. The results also suggest that the inhibitory effect of cigarette smoke on steroids is reversible, because withdrawal of CSC from cells results in the restoration of dexamethasone-induced activation of ENaC. However, the present study is based on cultured lung epithelial cells and there were no other cytotoxic effects detected at the CSC doses used. The reversibility in smokers' lungs would be more complex, depending at least on the dose of cigarette smoke and the extent of damage to lung epithelia.

In summary, the present study reveals a mechanism that explains an association between cigarette smoke condensate and $\alpha-\mathrm{ENaC}$ expression, which might be responsible for change in fluid movement in smokers' lungs. The results also suggest a difference between the response of smokers and nonsmokers to steroid therapy. These findings at the molecular level provide new leads for future studies in pulmonary 
oedema, acute lung injury and steroid therapy in smokers' lungs.

\section{REFERENCES}

1 Matthay MA, Zimmerman GA, Esmon C, et al. Future research directions in acute lung injury: summary of a National Heart, Lung, and Blood Institute working group. Am J Respir Crit Care Med 2003; 167: 1027-1035.

2 Ware LB, Matthay MA. The acute respiratory distress syndrome. N Engl J Med 2000; 342: 1334-1349.

3 Folkesson HG, Matthay MA. Alveolar epithelial ion and fluid transport: recent progress. Am J Respir Cell Mol Biol 2006; 35: 10-19.

4 Canessa CM, Schild L, Buell G, et al. Amiloride-sensitive epithelial $\mathrm{Na}^{+}$channel is made of three homologous subunits. Nature 1994; 367: 463-467.

5 Hummler E, Barker P, Gatzy J, et al. Early death due to defective neonatal lung liquid clearance in $\alpha$-ENaCdeficient mice. Nat Genet 1996; 12: 325-328.

6 Egli M, Duplain H, Lepori M, et al. Defective respiratory amiloride-sensitive sodium transport predisposes to pulmonary oedema and delays its resolution in mice. J Physiol 2004; 560: 857-865.

7 Kerem E, Bistritzer T, Hanukoglu A, et al. Pulmonary epithelial sodium-channel dysfunction and excess airway liquid in pseudohypoaldosteronism. N Engl J Med 1999; 341: 156-162.

8 Hanukoglu A, Bistritzer T, Rakover Y, Mandelberg A. Pseudohypoaldosteronism with increased sweat and saliva electrolyte values and frequent lower respiratory tract infections mimicking cystic fibrosis. I Pediatr 1994; 125: 752-755.

9 Milner D. The physiological effects of smoking on the respiratory system. Nurs Times 2004; 100: 56-59.

10 Iribarren C, Jacobs DR Jr, Sidney S, Gross MD, Eisner MD. Cigarette smoking, alcohol consumption, and risk of ARDS: a 15-year cohort study in a managed care setting. Chest 2000; 117: 163-168.

11 Lundberg JM, Martling CR, Saria A, Folkers K, Rosell S. Cigarette smoke-induced airway oedema due to activation of capsaicin-sensitive vagal afferents and substance $\mathrm{P}$ release. Neuroscience 1983; 10: 1361-1368.

12 Ware LB, Matthay MA. Clinical practice. Acute pulmonary edema. N Engl J Med 2005; 353: 2788-2796.

13 Tchepichev S, Ueda J, Canessa C, Rossier BC, O'Brodovich $\mathrm{H}$. Lung epithelial $\mathrm{Na}$ channel subunits are differentially regulated during development and by steroids. Am J Physiol 1995; 269: C805-C812.

14 Folkesson HG, Norlin A, Wang Y, Abedinpour P, Matthay MA. Dexamethasone and thyroid hormone pretreatment upregulate alveolar epithelial fluid clearance in adult rats. J Appl Physiol 2000; 88: 416-424.

$15 \mathrm{Chu} \mathrm{S}$, Ferro TJ. Identification of a hydrogen peroxideinduced PP1-JNK1-Sp1 signaling pathway for gene regulation. Am J Physiol Lung Cell Mol Physiol 2006; 291: L983-L992.

16 Chow CK. Cigarette smoking and oxidative damage in the lung. Ann N Y Acad Sci 1993; 686: 289-298.

17 Chaudhuri R, Livingston E, McMahon AD, Thomson L, Borland W, Thomson NC. Cigarette smoking impairs the therapeutic response to oral corticosteroids in chronic asthma. Am J Respir Crit Care Med 2003; 168: 1308-1311.

18 Van Overveld FJ, Demkow U, Gorecka D, De Backer WA, Zielinski J. Differences in responses upon corticosteroid therapy between smoking and non-smoking patients with COPD. J Physiol Pharmacol 2006; 57: Suppl. 4, 273-282.

19 Chalmers GW, Macleod KJ, Little SA, Thomson LJ, McSharry CP, Thomson NC. Influence of cigarette smoking on inhaled corticosteroid treatment in mild asthma. Thorax 2002; 57: 226-230.

20 Matthay MA, Folkesson HG, Clerici C. Lung epithelial fluid transport and the resolution of pulmonary edema. Physiol Rev 2002; 82: 569-600.

21 Mairbaurl H. Role of alveolar epithelial sodium transport in high altitude pulmonary edema (HAPE). Respir Physiol Neurobiol 2006; 151: 178-191.

22 Jain M, Sznajder JI. Effects of hypoxia on the alveolar epithelium. Proc Am Thorac Soc 2005; 2: 202-205.

23 Sartori C, Matthay MA. Alveolar epithelial fluid transport in acute lung injury: new insights. Eur Respir J 2002; 20: 1299-1313.

24 van Leeuwen DM, Gottschalk RW, van Herwijnen $\mathrm{MH}$, Moonen EJ, Kleinjans JC, van Delft JH. Differential gene expression in human peripheral blood mononuclear cells induced by cigarette smoke and its constituents. Toxicol Sci 2005; 86: 200-210.

25 Hellermann GR, Nagy SB, Kong X, Lockey RF, Mohapatra SS. Mechanism of cigarette smoke condensateinduced acute inflammatory response in human bronchial epithelial cells. Respir Res 2002; 3: 22.

26 Gao S, Chen K, Zhao Y, et al. Transcriptional and posttranscriptional inhibition of lysyl oxidase expression by cigarette smoke condensate in cultured rat fetal lung fibroblasts. Toxicol Sci 2005; 87: 197-203.

27 Gueorguiev VD, Cheng SY, Sabban EL. Prolonged activation of cAMP-response element-binding protein and ATF-2 needed for nicotine-triggered elevation of tyrosine hydroxylase gene transcription in PC12 cells. J Biol Chem 2006; 281: 10188-10195.

28 Kasai A, Hiramatsu N, Hayakawa K, Yao J, Maeda S, Kitamura M. High levels of dioxin-like potential in cigarette smoke evidenced by in vitro and in vivo biosensing. Cancer Res 2006; 66: 7143-7150.

29 Pulling LC, Vuillemenot BR, Hutt JA, Devereux TR, Belinsky SA. Aberrant promoter hypermethylation of the death-associated protein kinase gene is early and frequent in murine lung tumors induced by cigarette smoke and tobacco carcinogens. Cancer Res 2004; 64: 3844-3848.

30 Song S, Lippman SM, Zou Y, Ye X, Ajani JA, Xu XC. Induction of cyclooxygenase-2 by benzo[a]pyrene diol epoxide through inhibition of retinoic acid receptor-beta 2 expression. Oncogene 2005; 24: 8268-8276.

31 Barker PM, Walters DV, Markiewicz M, Strang LB. Development of the lung liquid reabsorptive mechanism in fetal sheep: synergism of triiodothyronine and hydrocortisone. J Physiol 1991; 433: 435-449.

32 Lin HH, Zentner MD, Ho HL, Kim KJ, Ann DK. The gene expression of the amiloride-sensitive epithelial sodium channel $\alpha$-subunit is regulated by antagonistic effects between glucocorticoid hormone and Ras pathways in salivary epithelial cells. J Biol Chem 1999; 274: 21544-21554. 
33 Xinmin D, Yunyou D, Chaosheng P, et al. Dexamethasone treatment attenuates early seawater instillation-induced acute lung injury in rabbits. Pharmacol Res 2006; 53: 372-379.
34 Funda A, Guniz M, Sibel E, Huseyin O. The effects of intratracheal dexamethasone on acute lung injury in rabbits - experimental study. Middle East J Anesthesiol 2005; 18: 161-171. 